\title{
Corrosion Inhibition of Carbon Steel in 1 M Sulphuric Acid Solution by Extract of Eucalyptus globulus Leaves Cultivated in Tunisia Arid Zones
}

\author{
Mohamed Tezeghdenti ${ }^{1}$ Leila Dhouibi ${ }^{1} \cdot$ Naceur Etteyeb $^{1,2}$
}

Received: 4 February 2015/Revised: 4 May 2015 / Accepted: 5 May 2015/Published online: 16 May 2015

(c) Springer International Publishing AG 2015

\begin{abstract}
The corrosion inhibition effect of the methanolic extract of Eucalyptus globulus leaves as an eco-friendly green inhibitor for corrosion control of carbon steel in $1 \mathrm{M}$ $\mathrm{H}_{2} \mathrm{SO}_{4}$ solution was studied using weight loss measurements and different electrochemical methods. It was found that $E$. globulus extract acts as a strong inhibitor. Results showed that this compound acts as a mixed-type inhibitor. As the inhibitor concentration increased, the charge transfer resistance of carbon steel increased and double layer capacitance decreased. The results of weight loss measurements were in good agreement with other electrochemical methods results. It was found that this green inhibitor acts through adsorption on the metal surface. In addition, adsorption obeys the Langmuir isotherm.
\end{abstract}

Keywords Eucalyptus globulus · Carbon steel · Eco-friendly inhibitor · Electrochemical methods

\section{Introduction}

Acid solutions are generally used for the removal of undesirable scale and rust in several industrial processes. Hydrochloric and sulphuric acids are widely used in the pickling processes of metals [1]. The use of inhibitors is

Naceur Etteyeb

naceur.etteyeb@gmail.com

1 Laboratoire Mécanique Appliquée et Ingénierie (Équipe COPROMET), ENIT, Université de Tunis-El-Manar, BP 37, 1002 Tunis Belvédère, Tunisia

2 Higher Institute of Applied Biology of Medenine, University of Gabes, Route El Jorf, El Fja 4111, BP 522, Gabès, Tunisia one of the best methods of protecting metals against corrosion $[2,3]$.

Most of the well-known acid inhibitors are organic compounds containing nitrogen, sulphur and oxygen in their functional groups with aromatic and heterocyclic rings [420]. These organic compounds can be absorbed on the metal surface, block the active sites on the surface and thereby reduce the corrosion rate. Most of investigated compounds are toxic and cause severe environmental hazards.

Some investigations have in recent times been made into the corrosion inhibiting properties of natural products of plant origin, and some natural products have been found to generally exhibit good inhibition efficiencies [21-35]. The significance of this area of research is primarily due to the fact that natural products are environmentally friendly and ecologically acceptable. The yield of these natural products as well as the corrosion inhibition abilities of the plant extracts vary widely depending on the part of the plant [33, 35,36 and its location [37]. One compound effective in a certain medium with a given metal may be ineffective for the same metal in another medium [31].

The use of natural products as corrosion inhibitors have been widely reported by several authors. The corrosion inhibition activity of plant extracts could be due to the presence of heterocyclic constituents like alkaloids, flavonoids, etc., even the presence of tannins, cellulose and polycyclic compounds normally enhances the film formation over the metal surface, thus aiding corrosion.

The aim of this paper is to extract and to test methanolic extract of Eucalyptus globulus (E. globulus) as corrosion inhibitor for steel in $1 \mathrm{M} \mathrm{H}_{2} \mathrm{SO}_{4}$ solution. The study is conducted by weight loss, polarisation curves, and electrochemical impedance spectroscopy methods. E. globulus belongs to Myrtaceae family and contains l'Eucalyptol (1,8-cineole) [38]. 


\section{Materials and Methods}

\subsection{Inhibitor Preparation}

Eucalyptus globulus (E. globulus) plant was collected in March, 2012 in the region of Medenine, Tunisia. E. globulus leaves were air dried 30 days in the laboratory at room temperature, before using them for the preparation of the extract. The extraction was performed by the soxhlet technique for $6 \mathrm{~h}$ with the methanol as solvent of extraction. The extracted solution was concentrated until extract solidification. This solid extract was used to study the corrosion inhi-

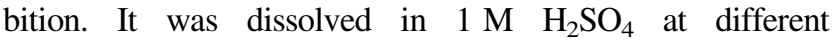
concentrations ranging from 0.5 to $1.5 \mathrm{~g} \mathrm{~L}^{-1}$ [39]. The test solutions are freshly prepared before each experiment.

\subsection{Specimen Preparation}

Corrosion tests were performed on a carbon steel of the following percentage composition (wt \%): Fe $99.52 \%$, C $0.22 \%$, Si $0.024 \%$, Mn $0.089 \%$, S $0.004 \%$, Ni $0.014 \%$, Cr $0.009 \%, \mathrm{Al} 0.034 \%, \mathrm{~V} 0.016 \%$, Ti $0.003 \%, \mathrm{Cu}$ $0.022 \%$ and $\mathrm{P} 0.046 \%$, which were abraded successively with fine grade emery papers of 120 to 1200 grade. The specimens were washed thoroughly with double distilled water and finally degreased with acetone and dried at room temperature.

\subsection{Electrolyte}

The aggressive solution $\left(1 \mathrm{M} \mathrm{H}_{2} \mathrm{SO}_{4}\right)$ is prepared by dilution of analytical grade $98 \% \mathrm{H}_{2} \mathrm{SO}_{4}$ with bidistilled water in the absence and presence of the green inhibitor in the concentration range of 0.5 to $1.5 \mathrm{~g} \mathrm{~L}^{-1}$.

\subsection{Weight Loss Method}

Weight loss measurements were performed on the carbon steel samples in a rectangular form of size $7 \times 3 \times 0.5 \mathrm{~cm}$ in $1 \mathrm{M} \mathrm{H}_{2} \mathrm{SO}_{4}$ solution in the presence and absence of different concentrations of E. globulus extract. Every sample was weighed by an electronic balance, and then placed in the acid solution $(150 \mathrm{~mL})$. The duration of the immersion was 90 days at the ambient temperature. After immersion, the surface of the specimen was chemically cleaned according to the standard procedure ASTM G1-90 (reapproved 1999) [40], and the sample was weighed again in order to calculate the inhibition efficiency $\left(\mathrm{IE}_{w} \%\right)$ and the corrosion rate $\left(\mathrm{CR}_{w}\right)$. The experiments were performed in triplicate and the average value of the weight loss was noted. For each experiment, a freshly prepared solution was used.
$\operatorname{IE}_{w}(\%)=\frac{w_{0}-w_{1}}{w_{0}} \times 100$,

where $w_{i}$ and $w_{0}$ are the weight loss values in the presence and absence of the green inhibitor, respectively.

The corrosion rate $\left(\mathrm{CR}_{w}\right)$ of mild steel was calculated using the relation:

$\mathrm{CR}_{w}=\frac{87.6 \times \Delta w}{A t d}\left(\mathrm{~mm} \mathrm{year}^{-1}\right)$,

where $\Delta w$ is the weight loss of carbon steel (mg), $A$ is the area of the coupon $\left(\mathrm{cm}^{2}\right), t$ the exposure time (h), and $d$ is the density of carbon steel $\left(\mathrm{g} \mathrm{cm}^{-3}\right)$.

\subsection{Electrochemical Studies}

For Tafel polarisation and A.C. impedance studies, carbon steel specimens embedded in resin with an exposed crosssectional area of $0.29 \mathrm{~cm}^{2}$ were used as the working electrode. The specimens were polished with a sequence of emery papers of various grades (120-1200) washed with double distilled water before usage and finally dried by warm air. These cleaned specimens were kept in desiccators until the time of experiment. Platinum and a standard calomel electrode (SCE) were employed as counter and reference electrodes, respectively. Thus all potentials reported are referred to SCE. The experimental temperature was $25 \pm 1{ }^{\circ} \mathrm{C}$.

The polarisation and A.C. impedance experiments were carried out by a PGSTAT consisting of a model AUTOLAB.

Tafel polarisation sweep was conducted in the potential range $\pm 0.25 \mathrm{mV}$ versus open circuit potential (O.C.P.) at a scan rate of $1 \mathrm{mV} \mathrm{s}^{-1}$, the potential was stabilized at free potential during $10 \mathrm{~min}$.

The linear Tafel segments of anodic and cathodic curves were extrapolated to corrosion potential to obtain corrosion current densities $\left(j_{\text {corr }}\right)$. The inhibition efficiency $\left(\mathrm{IE}_{j} \%\right)$ was evaluated from the measured $j_{\text {corr }}$ values using the relationship:

$\mathrm{IE}_{j}(\%)=\frac{j_{\text {corr }}^{0}-j_{\text {corr }}^{\mathrm{inh}}}{j_{\text {corr }}^{0}} \times 100$,

where $j_{\text {corr }}^{0}$ and $j_{\text {corr }}^{\text {inh }}$ are the corrosion current in the absence and in the presence of the green inhibitor, respectively.

Electrochemical Impedance Spectroscopy (EIS) measurements were carried out over a frequency range of $100 \mathrm{kHz}$ to $10 \mathrm{mHz}$ with five points per decade; a sine wave with $10 \mathrm{mV}$ amplitude was used to perturb the system. The impedance diagrams are given in the Nyquist representation. Experiments are repeated three times to ensure the reproducibility.

The charge transfer resistance values $\left(R_{\mathrm{t}}\right)$ were obtained from the diameter of the semicircles of the Nyquist plots. 
The inhibition efficiency ( $\mathrm{IE}_{\mathrm{EIS}} \%$ ) of the inhibitor has been found from the charge transfer resistance values using the following equation:

$\operatorname{IE}_{\mathrm{EIS}}(\%)=\frac{R_{\mathrm{t}}^{\mathrm{inh}}-R_{\mathrm{t}}^{0}}{R_{\mathrm{t}}^{\text {inh }}} \times 100$

where $R_{\mathrm{t}}^{0}$ and $R_{\mathrm{t}}^{\text {inh }}$ are the charge transfer resistance in the absence and in the presence of the green inhibitor, respectively. All electrochemical measurements were done in unstirred and non de-aerated solutions.

\section{Results and Discussions}

\subsection{Weight Loss Studies}

Figure 1 represents the effect of E. globulus extract concentration on inhibition efficiency in $1 \mathrm{M} \mathrm{H}_{2} \mathrm{SO}_{4}$. The results collected show that the methanolic extract inhibited the corrosion of carbon steel in $1 \mathrm{M} \mathrm{H}_{2} \mathrm{SO}_{4}$ solutions. The corrosion rate was found depending on the inhibitor concentrations. The increase in the methanolic extract concentration increases the inhibition efficiency $\mathrm{EI}_{w} \%$ to about $85 \%$ at $1.5 \mathrm{~g} \mathrm{~L}^{-1}$. The inhibitory action of natural compounds against steel corrosion can be attributed to the component adsorption on the metal surface. This adsorption limits the dissolution of metal by blocking its corrosion sites and hence decreasing the weight loss with the increasing efficiency as the concentration increases.

\subsection{Polarisation Curves}

Polarisation curves for carbon steel in $1 \mathrm{M} \mathrm{H}_{2} \mathrm{SO}_{4}$ in the absence and presence of $E$. globulus leaves extract at various concentrations are shown in Fig. 2.

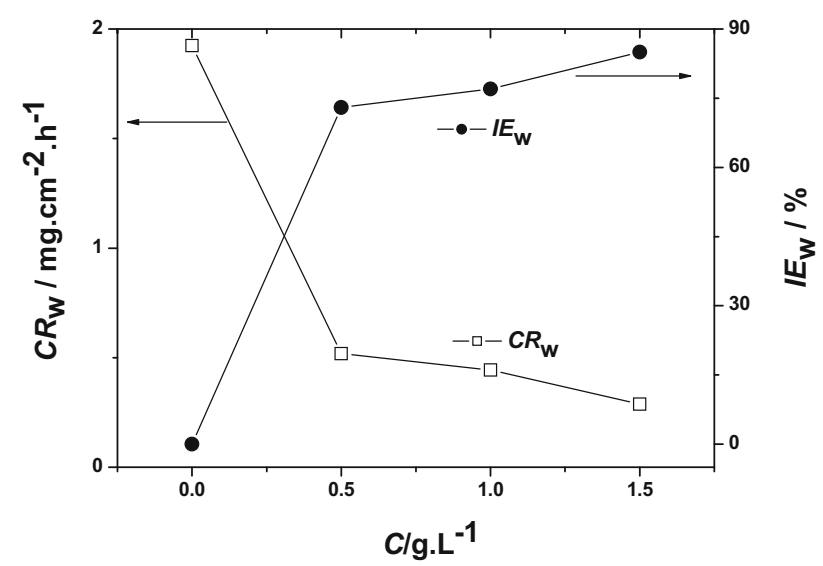

Fig. 1 Variation of corrosion rate and inhibition efficiency of carbon steel in $1 \mathrm{M} \mathrm{H}_{2} \mathrm{SO}_{4}$ in the absence and presence of E. globulus methanolic extract

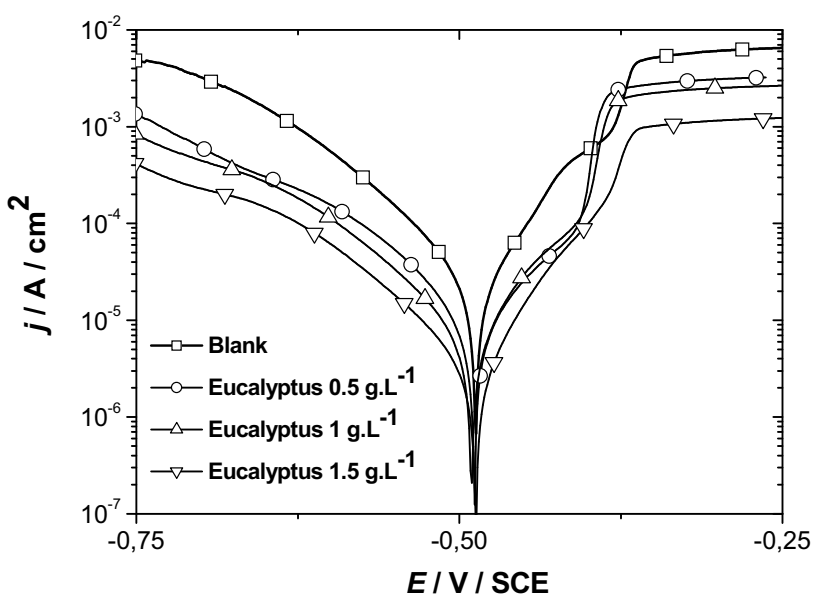

Fig. 2 Polarisation curves for carbon steel in $1 \mathrm{M} \mathrm{H}_{2} \mathrm{SO}_{4}$ in the absence and presence of different concentrations of $E$. globulus inhibitor

Electrochemical parameters such as corrosion potential $\left(E_{\text {corr }}\right)$, corrosion current density $\left(j_{\text {corr }}\right)$ and cathodic and anodic tafel slopes $\left(b_{\mathrm{c}}, b_{\mathrm{a}}\right)$ were determinated using the Stern and Geary equation in the Tafel regions (near $E_{\text {corr }}$ ) (Table 1). The inhibition efficiency $\left(\mathrm{IE}_{j} \%\right)$ was calculated from the relationship (Eq. 3) (Table 1).

According to Stern and Geary [41], one can express the current density $j$ near the open-circuit potential by

$j=j_{\text {corr }}\left\{\exp \left[b_{\mathrm{a}}\left(E-E_{\text {corr }}\right]-\exp \left[b_{\mathrm{c}}\left(E-E_{\text {corr }}\right]\right\}\right.\right.$.

Figure 3 shows an example of the calculation results by nonlinear regression using the Stern and Geary equation.

The result obtained by applying this equation shows a good concordance with the experimental results.

The nominal corrosion rate in terms of corrosion penetration $\left(\mu \mathrm{m}\right.$ year $\left.^{-1}\right)$ can be calculated using Faraday's law as [42]

$\mathrm{CR}_{j}=\frac{K a_{w}}{n F d} j_{\mathrm{corr}}=\alpha j_{\mathrm{corr}}$,

where $K=315,360$ is a units conversion factor, $F$ is the faraday constant $\left(F=96,485 \mathrm{C} \mathrm{mol}^{-1}\right), n$ is the number of moles of electrons transferred, $a_{w}$ is the atomic weight in grams, $d$ is the density of the metal in $\mathrm{g} \mathrm{cm}^{-3}$ and $j_{\text {corr }}$ is the corrosion current density in $\mu \mathrm{A} \mathrm{cm}^{-2}$. The value of the constant $\alpha$ for steel is approximately $\alpha_{\mathrm{Fe}}=11.6 \mu \mathrm{A}^{-1} \mathrm{~cm}^{2} \mu \mathrm{m}$ year ${ }^{-1}$.

From the Table 1, it is clear that corrosion potential $\left(E_{\text {corr }}\right)$ did not change after the addition of the methanolic extract at various concentrations. The change in $\beta_{\mathrm{a}}$ and $\beta_{\mathrm{c}}$ values as shown in Table 1 indicates that the addition of $E$. globulus extract modifies the mechanism of anodic dissolution as well as cathodic hydrogen evolution. But, in the present situation, it is very difficult to decide whether it is the cathodic reaction which is predominantly retarded or the anodic reaction. 
Table 1 Polarisation parameters for carbon steel in $1 \mathrm{M} \mathrm{H}_{2} \mathrm{SO}_{4}$ in the absence and presence of E. globulus extract at various concentrations

\begin{tabular}{llccccc}
\hline$C\left(\mathrm{~g} \mathrm{~L}^{-1}\right)$ & $\left.E(\mathrm{mV} \mathrm{ECS})^{-1}\right)$ & $j_{\text {corr }}\left(\mu \mathrm{A} \mathrm{cm}^{-2}\right)$ & $\beta_{\mathrm{a}}\left(\mathrm{mV} \mathrm{dec}^{-1}\right)$ & $\left.\beta_{\mathrm{c}}(\mathrm{mV} \mathrm{dec})^{-1}\right)$ & $\mathrm{IE}_{j} \%$ & $\mathrm{CR}_{j}\left(\mu \mathrm{m} \mathrm{year}{ }^{-1}\right)$ \\
\hline (Blank) 0 & -0.484 & 28.6 & 117 & 145 & - & 331.7 \\
0.5 & -0.482 & 8.2 & 85 & 98 & 71.3 & 95.1 \\
1.0 & -0.491 & 7.5 & 80 & 84 & 73.7 & 87.0 \\
1.5 & -0.490 & 4.1 & 73 & 82 & 47.6 \\
\hline
\end{tabular}

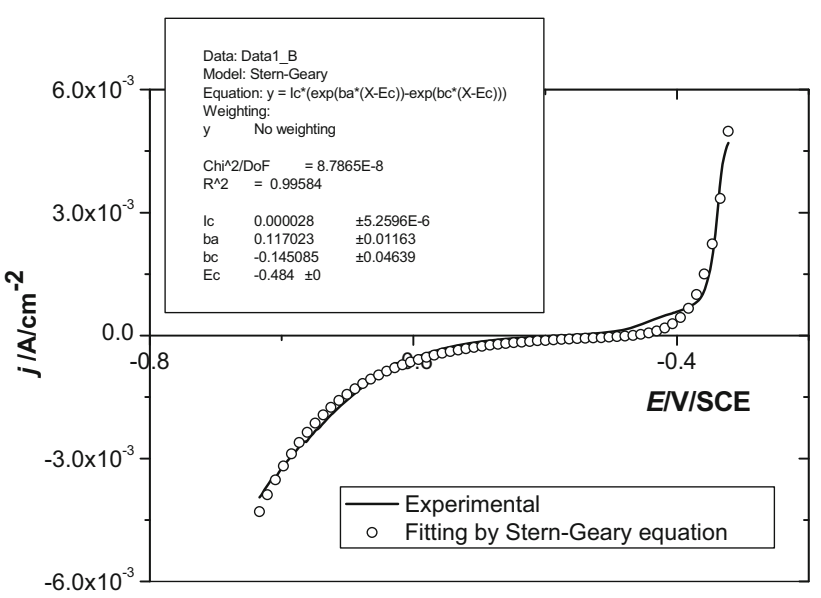

Fig. 3 Experimental and calculated $j-E$ curves to evaluate the electrochemical parameters (circle) experimental data; (solid line) calculated data

This result indicated that the methanolic extract can be classified as mixed-type inhibitor in $1 \mathrm{M} \mathrm{H}_{2} \mathrm{SO}_{4}$ solution.

It is illustrated from the data of Table 1 that the addition of Eucalyptus extract decreases the corrosion current density. The decrease in $j_{\text {corr }}$ values can be due to the adsorption of the methanolic extract on the carbon steel surface. This idea was investigated in a separate section by plotting a suitable adsorption isotherm. Moreover, it can be clearly seen that the inhibition efficiency of the methanolic extract increases with the inhibitor concentration. This behaviour shows that $E$. globulus extract acts as a good inhibitor for the corrosion of carbon steel in $1 \mathrm{M} \mathrm{H}_{2} \mathrm{SO}_{4}$ media.

The presence of the methanolic extract of E. globulus at a concentration of $1.5 \mathrm{~g} \mathrm{~L}^{-1}$ in the acidic medium $\left(1 \mathrm{M} \mathrm{H}_{2} \mathrm{SO}_{4}\right)$ reduced the corrosion rate $\left(\approx 47 \mu \mathrm{m} \mathrm{year}^{-1}\right)$. However, this inhibitor does not completely prevent corrosion.

\subsection{EIS Measurements}

The corrosion behaviour of carbon steel in $1 \mathrm{M} \mathrm{H}_{2} \mathrm{SO}_{4}$ solution in the absence and presence of $E$. globulus leaves extract was investigated by EIS at $25 \pm 1{ }^{\circ} \mathrm{C}$ after $10 \mathrm{~min}$ of immersion. Surface properties, electrode kinetics and mechanistic information can be obtained from the impedance diagrams [43-46].

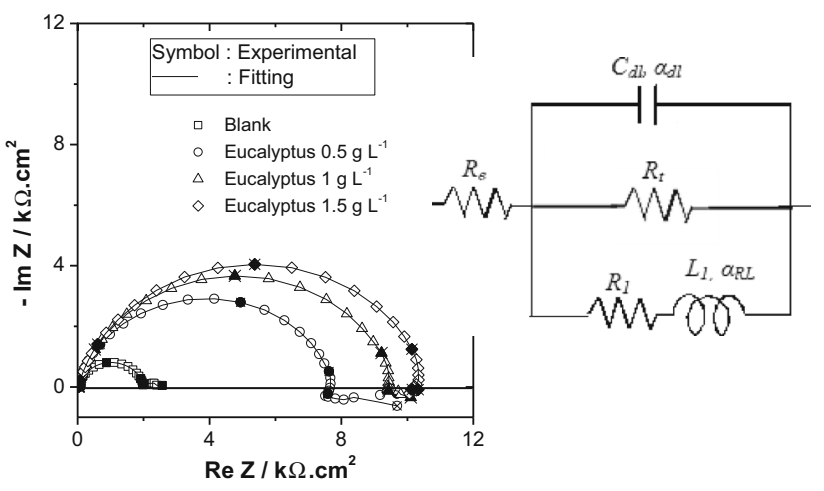

Fig. 4 Nyquist plot of carbon steel in $1 \mathrm{M} \mathrm{H}_{2} \mathrm{SO}_{4}$ solution in the absence and presence of different concentrations of E. globulus inhibitor at $298 \mathrm{~K}$ (experimental measurement) and fitted results using equivalent circuit model, $(1 R C-1 R L)$

Figure 4 shows the results of EIS experiments in the Nyquist representation. After analysing the shape of the Nyquist plots, it is concluded that the Nyquist plots showed a depressed capacitive loop in the high-frequency (HF) range and small inductive loop in the low-frequency (LF) range indicating the occurrence of a Faradic process on free electrode sites. The HF capacitive loop can be attributed to the charge transfer reaction and time constant of the electric double layer. On the other hand, the LF inductive loop may be attributed to the relaxation of intermediates controlling the anodic process resulting from adsorption species such as $\mathrm{FeSO}_{4}[47]$, or inhibitor species $[48,49]$ on the electrode surface. It might also be attributed to the redissolution of the passivated surface at LF [50].

Bockris et al. [51] proposed that Fe electro-dissolution in acidic sulphate solutions depends primarily on the adsorbed intermediate $\mathrm{FeOH}_{\mathrm{ads}}$ as follows:

$\mathrm{Fe}+\mathrm{OH}^{-} \leftrightharpoons \mathrm{FeOH}_{\mathrm{ads}}+\mathrm{H}^{+}+\mathrm{e}$

$\mathrm{FeOH}_{\text {ads }} \stackrel{\text { rds }}{\longrightarrow} \mathrm{FeOH}^{+}+\mathrm{e}$

$\mathrm{FeOH}^{+}+\mathrm{H}^{+} \rightleftarrows \mathrm{Fe}^{2+}+\mathrm{H}_{2} \mathrm{O}$

The cathodic hydrogen evolution follows the steps:

$\mathrm{Fe}+\mathrm{H}^{+} \leftrightharpoons\left(\mathrm{FeH}^{+}\right)_{\mathrm{ads}}$ 


$$
\begin{aligned}
& \left(\mathrm{FeH}^{+}\right)_{\mathrm{ads}}+\mathrm{e} \leftrightarrows(\mathrm{FeH})_{\mathrm{ads}} \\
& (\mathrm{FeOH})_{\mathrm{ads}}+\mathrm{H}^{+}+\mathrm{e} \leftrightharpoons \\
& \mathrm{Fe}+\mathrm{H}_{2} .
\end{aligned}
$$

The corrosion rate of iron in $\mathrm{H}_{2} \mathrm{SO}_{4}$ solutions is controlled by both hydrogen evolution reaction and dissolution reaction of iron.

Another mechanism involving two adsorbed intermediates has been used to account for the retardation of $\mathrm{Fe}$ anodic dissolution in the presence of an inhibitor [52]:

$$
\begin{aligned}
& \mathrm{Fe}+\mathrm{H}_{2} \mathrm{O} \leftrightharpoons \mathrm{Fe} \cdot \mathrm{H}_{2} \mathrm{O}_{\text {ads }} \\
& \mathrm{Fe} \cdot \mathrm{H}_{2} \mathrm{O}_{\text {ads }}+\mathrm{Y} \leftrightarrows \mathrm{FeOH}_{\text {ads }}^{-}+\mathrm{H}^{+}+\mathrm{Y} \\
& \mathrm{Fe} \cdot \mathrm{H}_{2} \mathrm{O}_{\text {ads }}+\mathrm{Y} \leftrightarrows \mathrm{FeY}_{\text {ads }}+\mathrm{H}_{2} \mathrm{O} \\
& \mathrm{FeOH}_{\text {ads }}^{-} \stackrel{\text { rds }}{\longrightarrow} \mathrm{FeOH}_{\text {ads }}+\mathrm{e} \\
& \mathrm{FeY}_{\mathrm{ads}} \leftrightharpoons \mathrm{FeY}_{\mathrm{ads}}^{+}+\mathrm{e} \\
& \mathrm{FeOH}_{\text {ads }}+\mathrm{FeY}_{\text {ads }}^{+} \leftrightharpoons \mathrm{FeY}_{\text {ads }}+\mathrm{FeOH}^{+} \\
& \mathrm{FeOH}^{+}+\mathrm{H}^{+} \leftrightarrows \mathrm{Fe}^{2+}+\mathrm{H}_{2} \mathrm{O},
\end{aligned}
$$

where Y represents the inhibitor species.

The EIS spectra are simulated by the equivalent circuit shown in Fig. 4.

The equivalent circuit consists of the double layer capacitance $\left(C_{\mathrm{dl}}\right)$ in parallel to the charge transfer resistance $\left(R_{\mathrm{t}}\right)$, which is in parallel to the series of inductive elements $L_{1}$ and $R_{\mathrm{L}}$. The presence of $L$ in the impedance spectra in the presence of the inhibitor indicates that steel is always dissolved by the direct charge transfer at the E. globulus adsorbed in the steel surface [53]. The results of regression calculations with a simplex method for this system are overlaid on Fig. 4. The comparison of experimental and calculated spectra corroborates the adequacy of the equivalent circuit adopted.

The impedance parameters such as charge transfer resistance $\left(R_{\mathrm{t}}\right.$ : diameter of high frequency loop), derived double layer capacitance $\left(C_{\mathrm{dl}}\right)$ and inhibition efficiency $\left(\mathrm{IE}_{\mathrm{EIS}} \%\right)$ are listed in Table 2.

The values of the double layer capacitance were obtained at maximum frequency $\left(f_{\mathrm{m}}\right)$, at which the imaginary

Table 2 Impedance parameters for carbon steel in $1 \mathrm{M} \mathrm{H}_{2} \mathrm{SO}_{4}$ solution in the absence and presence of E. globulus extract at various concentrations

\begin{tabular}{lccl}
\hline$C\left(\mathrm{~g} \mathrm{~L}^{-1}\right)$ & $R_{\mathrm{t}}\left(\Omega \mathrm{cm}^{2}\right)$ & $C_{\mathrm{dl}}\left(\mu \mathrm{F} \mathrm{cm}^{-2}\right)$ & $\mathrm{IE}_{\mathrm{EIS}} \%$ \\
\hline (Blank) 0 & 1640 & 150 & - \\
0.5 & 7640 & 93 & 78.5 \\
1.0 & 9420 & 78 & 82.6 \\
1.5 & 10,272 & 52 & 84.1 \\
\hline
\end{tabular}

component of the Nyquist plot is maximal, and calculated using the following equation:

$C_{\mathrm{dl}}=\frac{1}{2 \pi f_{\mathrm{m}} R_{\mathrm{t}}}$.

where $C_{\mathrm{dl}}$ is the double layer capacitance $\left(\mu \mathrm{F} \mathrm{cm}{ }^{-2}\right), f_{\mathrm{m}}$ is the maximum frequency $(\mathrm{Hz})$ and $R_{\mathrm{t}}$ is the charge transfer resistance $\left(\Omega \mathrm{cm}^{2}\right)$.

The diameter of the capacitive loop in the presence of inhibitor is larger than that in the absence of inhibitor and increases with the inhibitor concentration. This indicates that the impedance of inhibited substrate increases with the inhibitor concentration.

The existence of the capacitive loops and disappearance of the low-frequency inductive loops when compared with the Nyquist diagram in the $1 \mathrm{M} \mathrm{H}_{2} \mathrm{SO}_{4}$ solutions without inhibitors and in the presence of E. globulus extract could be related to the gradual replacement of water molecules and/or hydroxyl ions by organic inhibitors on the surface of the metal.

It is apparent that as the concentration of the methanolic extract increased, the $R_{\mathrm{t}}$ values increased indicating decrease in the formation of intermediates that control the anodic process from metal dissolution and subsequently inhibition of corrosion. The increase of charge transfer resistance with the inhibitor concentration suggests that more inhibitor molecules are adsorbed on the metal surface at higher concentration leading to a greater surface coverage. The decrease in the capacity was caused by reduction in local dielectric constant and/or by increase in the thickness of the electrical double layer. This fact suggests that the inhibitor molecules act by adsorption at the metal/solution interface [54-58].

From Table 2, it is clear that the greatest effect was observed at $1.5 \mathrm{~g} \mathrm{~L}^{-1}$ of E. globulus extract which gives $R_{\mathrm{t}}$ value of 10,272 and $1640 \Omega \mathrm{cm}^{2}$ in $1 \mathrm{M} \mathrm{H}_{2} \mathrm{SO}_{4}$.

The data obtained from EIS are in good agreement with those obtained from polarisation curves method. It is concluded that the corrosion rate depends on the chemical nature of the electrolyte rather than the applied technique.

\subsection{Adsorption Isotherm}

Inhibition effects are based on the adsorption of molecules onto the metal surface to form an impermeable protective film and shielding it from the corrosive media. On the other hand, the adsorbed molecules can combine with the oxide layer on the metal (rust deposited) and react chemically to produce a more protective surface network by changing the film structure. The adsorption mechanism of organic compounds occurs either directly, on the basis of donoracceptor interactions between the relatively loosely bound electrons such as in anions and organic molecules and/or 

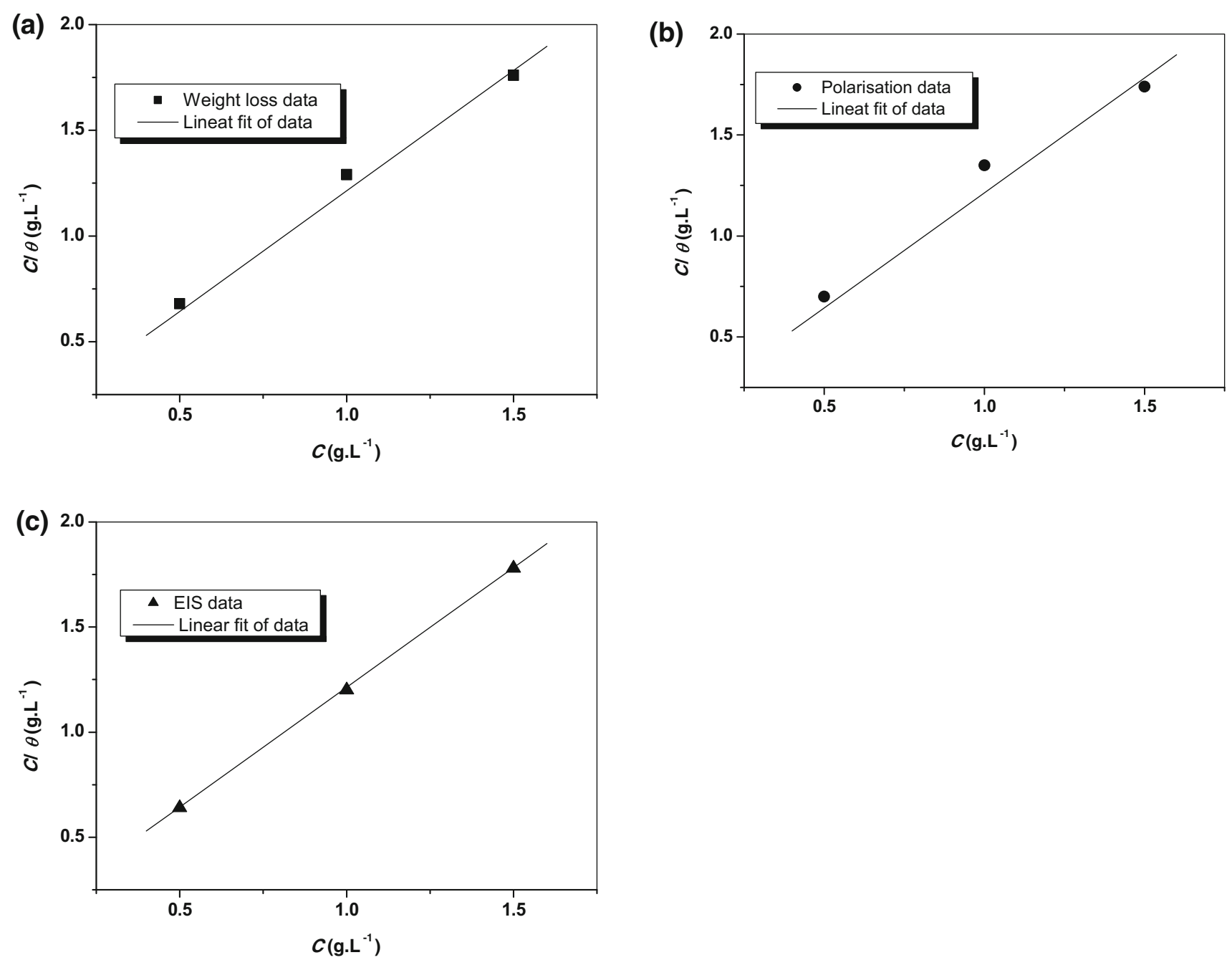

Fig. 5 Langmuir isotherm for the adsorption of E. globulus methanolic extract on the carbon steel surface: a (weight loss data), b (polarisation data) and $\mathbf{c}$ (EIS data)

the heterocyclic compound which has lone pair electrons, or the $\pi$-electrons with the vacant d-orbitals of metallic iron atoms. Some parameters such as organic molecule size, number of functional groups, polarity that contribute to the formation of a strong bond or the rate of adsorption of inhibitor compounds onto the surface could affect the adsorption mechanism or inhibition action [59].

The Langmuir adsorption isotherm provides a simple mechanistic picture of the adsorption process and gives rise to a relatively simple mathematical expression. The Langmuir adsorption isotherm may be written in the following rearranged form [60]:

$K C=\frac{\theta}{1-\theta}$.

Here $K$ is the equilibrium constant. It is convenient to rearrange the equation, yielding
$\frac{C}{\theta}=C+\frac{1}{K}$,

where $C$ is the concentration of inhibitor, $K$ is the adsorptive equilibrium constant, $\theta$ is the surface coverage.

The surface coverage, $\theta$, was determined using the following equations:

$\theta=\frac{\mathrm{IE} \%}{100}$.

For all the three methods used in this study (weight loss, polarisation, and EIS), a plot of $C / \theta$ against $C$ gave straight lines with the slope of unit (Fig. 5). This means that the adsorption of the methanolic extract on the carbon steel surface obeys the Langmuir isotherm.

The free energy of adsorption $\left(\Delta G_{\mathrm{ads}}\right)$ was calculated using the results of different methods through the following equation [61]: 
Table 3 The values of free Gibs energy of adsorption calculated using the results of different electrochemical studies

\begin{tabular}{llll}
\hline Method & Weight loss & Polarisation & EIS \\
\hline$\Delta G_{\text {ads }}\left(\mathrm{kJ} \mathrm{g}^{-1}\right)$ & -13.55 & -13.38 & -14.04 \\
\hline
\end{tabular}

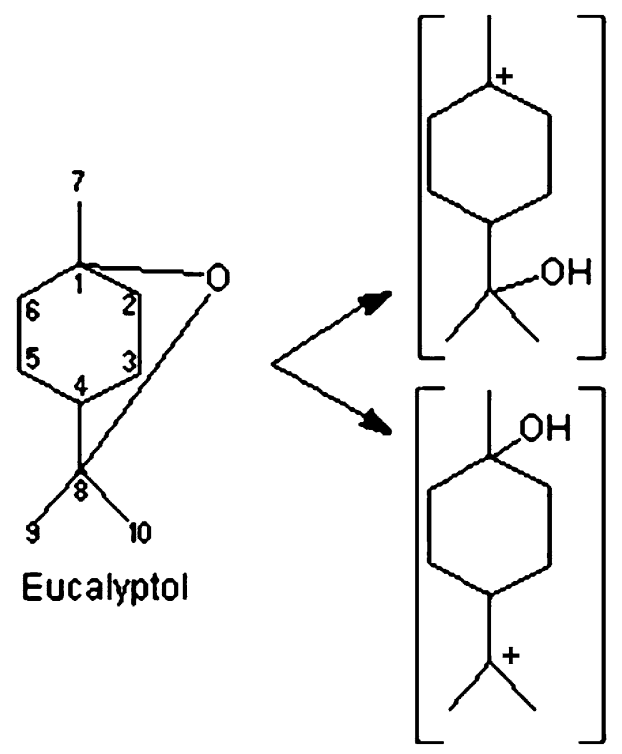

Fig. 6 Protonation of eucalyptol in acidic medium

$\Delta G_{\mathrm{ads}}=-R T \ln (55.5 K)$

The calculated values are given in Table 3 . The values of $\Delta G_{\text {ads }}$ from the different methods used were in good agreement with each other. $\Delta G_{\mathrm{ads}}$ values are around $-13 \mathrm{~kJ} \mathrm{~g}^{-1}\left(-13 \times \mathrm{M}, \mathrm{kJ} \mathrm{mol}^{-1}\right)$. Although the molecular weight of extract was not determined, $\Delta G_{\text {ads }}$ value was given in $\mathrm{kJ} \mathrm{g}^{-1}$ unit. The negative values of $\Delta G_{\text {ads }}$ are an indication of the spontaneous adsorption of inhibitor on the surface of the carbon steel [60].

In general, values of $\Delta G_{\text {ads }}$ up to $-20 \mathrm{~kJ} \mathrm{~mol}^{-1}$ were consistent with the electrostatic interaction between the charged molecules and the charged metal (physical adsorption). On the other hand, negative values less than $-40 \mathrm{~kJ} \mathrm{~mol}^{-1}$ involved sharing or transferring of electrons from the inhibitor molecules to the metal surface to form a co-ordinate type of bond (chemisorption) [62].

In this study, the calculated $\Delta G_{\text {ads }}$ values greater than $-40 \mathrm{~kJ} \mathrm{~mol}^{-1}$ indicate that the adsorption mechanism of the investigated inhibitor on carbon steel in $1 \mathrm{M} \mathrm{H}_{2} \mathrm{SO}_{4}$ solution is typical of chemisorption [62]. However, the methanolic extract of E. globulus contains Eucalyptol (1,8cineole). The latter can be easily protonated in the sulphuric acid solution because the molecule contains $\mathrm{O}$ atoms with lone pair electrons and $\pi$-electrons. Thus, they become cations, existing in equilibrium with the corresponding molecular form (Fig. 6).

Therefore, physical adsorption may take place due to electrostatic interaction between the protonated molecule and $\mathrm{FeSO}_{4}^{2-}$ species.

\section{Conclusions}

Based on the results of investigation, the following conclusions are drawn:

- Methanolic extract of E. globulus is a good eco-friendly green inhibitor for carbon steel in $1 \mathrm{M} \mathrm{H}_{2} \mathrm{SO}_{4}$ solutions and can be used to replace toxic chemicals.

- Inhibition efficiency value increases with the inhibitor concentration; the maximum inhibition efficiency was $84 \%$.

- Polarisation studies showed that E. globulus is a mixedtype inhibitor in $1 \mathrm{M} \mathrm{H}_{2} \mathrm{SO}_{4}$.

- EIS plots indicated that the charge transfer resistances increase with the increasing concentration of the extract.

- The data obtained from the three different methodspotentiodynamic polarisation, EIS and weight loss, are in good agreements.

- The corrosion inhibition was probably due to the adsorption of the green inhibitor on the metal surface without changing the mechanism of partial corrosion reaction and blocking its active sites.

- The data obtained from this study were fitted well into the Langmuir adsorption isotherm. Adsorption of the studied bio-inhibitor on the carbon steel surface in $1 \mathrm{M}$ $\mathrm{H}_{2} \mathrm{SO}_{4}$ represented a mixture of physical and chemical adsorption.

Conflict of interest On behalf of all authors, Naceur Etteyeb states that there is no conflict of interest.

\section{References}

1. Chauhan LR, Gunasekaran G (2007) corrosion inhibition of mild steel by plant extract in dilute $\mathrm{HCl}$ medium. Corros Sci 49: $1143-1161$

2. Eddy NO, Ebenso EE (2008) Adsorption and inhibitive properties of ethanol extracts of Musa sapientum peels as a green corrosion inhibitor of mild steel in $\mathrm{H}_{2} \mathrm{SO}_{4}$. Afr J Pure Appl Chem 2:46-54

3. Eddy NO, Stoyanov SR, Ebenso EE (2010) Fluoroquinolones as corrosion inhibitors for mild steel in acidic medium; experimental and theoretical studies. Int J Electrochem Sci 5:1127-1150

4. Negm NA, Elkholy YM, Zahran MK, Tawfik SM (2010) Corrosion inhibition efficiency and surface activity of benzothiazol3 -ium cationic schiff base derivatives in hydrochloric acid. Corros Sci 52:3523-3536 
5. Lagrenee M, Mernari B, Bouanis M, Traisnel M, Bentiss F (2002) Study of the mechanism and inhibiting efficiency of 3,5-bis(4methylthiophenyl)-4H-1,2,4-triazole on mild steel corrosion in acidic media. Corros Sci 44:573-588

6. Hegazy MA (2009) A novel Schiff base-based cationic gemini surfactants: synthesis and effect on corrosion inhibition of carbon steel in hydrochloric acid solution. Corros Sci 51:2610-2618

7. Zhang J, Gong XL, Yu HH, Du M (2011) The inhibition mechanism of imidazoline phosphate inhibitor for Q235 steel in hydrochloric acid medium. Corros Sci 53:3324-3330

8. Hegazy MA, Abdallah M, Ahmed H (2010) Novel cationic gemini surfactants as corrosion inhibitors for carbon steel pipelines. Corros Sci 52:2897-2904

9. Aljourani J, Raeissi K, Golozar MA (2009) Benzimidazole and its derivatives as corrosion inhibitors for mild steel in $1 \mathrm{M} \mathrm{HCl}$ solution. Corros Sci 51:1836-1843

10. Stanly JK, Parameswaran G (2010) Corrosion inhibition of mild steel in hydrochloric acid solution by Schiff base furoin thiosemicarbazone. Corros Sci 52:224-228

11. Tang Y, Yang X, Yang W, Chen Y, Wana R (2010) Experimental and molecular dynamics studies on corrosion inhibition of mild steel by 2-amino-5-phenyl-1,3,4-thiadiazole. Corros Sci 52:242-249

12. Lowmunkhong $P$, Ungthararak D, Sutthivaiyakit $P$ (2010) Tryptamine as a corrosion inhibitor of mild steel in hydrochloric acid solution. Corros Sci 52:30-36

13. Hasanov R, Bilge S, Bilgic S, Gece G, K1lıc Z (2010) Experimental and theoretical calculations on corrosion inhibition of steel in $1 \mathrm{M}$ $\mathrm{H}_{2} \mathrm{SO}_{4}$ by crown type polyethers. Corros Sci 52:984-990

14. Sadeghi ME, Shahrabi Farahani T, Neshati J (2012) 2-Butyne1,4-diol as a novel corrosion inhibitor for API X65 steel pipeline in carbonate/bicarbonate solution. Corros Sci 54:36-44

15. Hegazy MA, El-Tabei AS, Bedair AH, Sadeq MA (2012) An investigation of three novel nonionic surfactants as corrosion inhibitor for carbon steel in 0.5 $\mathrm{M} \mathrm{H}_{2} \mathrm{SO}_{4}$. Corros Sci 54:219-230

16. Palomar-Pardave $M$, Romero-Romo $M$ et al (2012) Influence of the alkyl chain length of 2 amino 5 alkyl 1,3,4 thiadiazole compounds on the corrosion inhibition of steel immersed in sulfuric acid solutions. Corros Sci 54:231-243

17. Issaadi S, Douadi T, Zouaoui A et al (2011) Novel thiophene symmetrical Schiff base compounds as corrosion inhibitor for mild steel in acidic media. Corros Sci 53:1484-1488

18. Atta AM, El-Azabawy OE, Ismail HS, Hegazy MA (2011) Novel dispersed magnetite core-shell nanogel polymers as corrosion inhibitors for carbon steel in acidic medium. Corros Sci 53:1680-1689

19. Doner A, Solmaz R, Ozcan M, Kardas G (2011) Experimental and theoretical studies of thiazoles as corrosion inhibitors for mild steel in sulphuric acid solution. Corros Sci 53:2902-2913

20. Li X, Deng S, Fu H (2011) Three pyrazine derivatives as corrosion inhibitors for steel in $1.0 \mathrm{M} \mathrm{H}_{2} \mathrm{SO}_{4}$ solution. Corros Sci 53:3241-3247

21. Ekpe UJ, Ebenso EE, Ibok UJ (1994) Inhibitory action of Azadirachta indica leaves extract on the corrosion of mild steel in $\mathrm{H}_{2} \mathrm{SO}_{4}$. J West Afr Sci Assoc 37:13-30

22. Ebenso EE, Ekpe UJ (1996) Kinetic study of corrosion and corrosion inhibition of mild steel in $\mathrm{H}_{2} \mathrm{SO}_{4}$ using Carica papaya leaves extract. West Afr J Biol Appl Chem 41:21-27

23. Avwiri GO, Igho FO (2001) Inhibitive action of Vernonia amygdalina on the corrosion of aluminium alloys in acidic media. Mater Lett 57:3705-3711

24. Ebenso EE, Ibok UJ, Ekpe UJ et al (2004) Corrosion inhibition studies of some plant extracts on aluminium in acidic medium. Trans SAEST 39:117-123

25. El-Etre AY, El-Tantawy Z (2006) Inhibition of metallic corrosion using Ficus extract. Port Electrochim Acta 24:347-356
26. Umoren SA, Obot IB, Ebenso EE, Okafor PC, Ogbobe O, Oguzie EE (2006) Gum arabic as a potential corrosion inhibitor for aluminium in alkaline medium and its adsorption characteristics. Anti Corros Methods Mater 53:277-282

27. Oguzie EE, Onuchukwu AI, Okafor PC, Ebenso EE (2006) Corrosion inhibition and adsorption behaviour of Occimum basiclicum extract on aluminium. Pigment Resin Technol 35:63-70

28. Oguzie EE (2006) Adsorption and corrosion inhibitive properties of Azadirachta indica in acid solutions. Pigment Resin Technol 35:334-340

29. Oguzie EE (2007) Corrosion inhibition of aluminium in acidic and alkaline media by Sansevieria trifasciata extract. Corros Sci 49:1527-1539

30. Ebenso EE, Eddy NO, Odiongenyi AO (2008) Corrosion inhibitive properties and adsorption behaviour of ethanol extract of Piper guinensis as a green corrosion inhibitor for mild steel in $\mathrm{H}_{2} \mathrm{SO}_{4}$. Afr J Pure Appl Chem 11:107-115

31. Okafor PC, Ekpe UJ, Ebenso EE, Umoren EM, Leizou KE (2005) Inhibition of mild steel corrosion in acidic medium by Allium sativum extracts. Bull Electrochem 21:347-352

32. Okafor PC, Ekpe UJ, Ebenso EE, Oguzie EE, Umo NS, Etor AR (2006) Extract of Allium cepa and Allium sativum as corrosion inhibitors of mild steel in $\mathrm{HCl}$ solution. Trans SAEST 41:82-87

33. Okafor PC, Osabor VI, Ebenso EE (2007) Eco-friendly corrosion inhibitors: inhibitive action of ethanol extracts of Garcinia kola for the corrosion of mild steel in $\mathrm{H}_{2} \mathrm{SO}_{4}$ solutions. Pigment Resin Technol 35:299-305

34. Okafor PC, Ebenso EE (2007) Inhibitive action of Carica papaya extracts on the corrosion of mild steel in acidic media and their adsorption characteristics. Pigment Resin Technol 36:134-140

35. Okafor PC, Ikpi ME, Uwah IE et al (2008) Inhibitory action of Phyllanthus amarus extracts on the corrosion of mild steel in acidic media. Corros Sci 50:2310-2317

36. Khuzhaev V, Aripova S (2000) Pseudocarpaine from Carica papaya. Chem Nat Compd 36:418-421

37. Ogan AU (1971) The basic constituents of the leaves of Carica papaya. Phytochemistry 10:2544-2547

38. Warot S (2006) Mémoire de fin de formation en Phyto-aromathérapie, les Eucalyptus utilisés en Aromathérapie

39. Mourya P, Banerjee S, Singh MM (2014) Corrosion inhibition of mild steel in acidic solution by Tagetes erecta (Marigold flower) extract as a green inhibitor. Corros Sci 85:352-363

40. Standard procedure ASTM G1-90 (reapproved 1999)

41. Stern M, Geary AL (1957) A theoretical analysis of the shape of polarisation curves. J Electrochem Soc 104:56-63

42. Morris W, Vico A, Vazquez M, de Sanchez SR (2002) Corrosion of reinforcing steel evaluated by means of concrete resistivity measurements. Corros Sci 44:81-99

43. Silverman DC, Carrico JE (1988) Electrochemical impedance technique-a practical tool for corrosion prediction. Corrosion 44:280-287

44. Lorenz WJ, Mansfeld F (1981) Determination of corrosion rates by electrochemical DC and AC methods. Corros Sci 21:647-672

45. Macdonald DD, Mckubre MC (1982) Impedance measurements in electrochemical systems. In: Bockris JOM, Conway BE, White RE (eds) Modern aspects of electrochemistry, vol 14. Plenum Press, New York, NY, p 61

46. Mansfeld F (1990) Electrochemical impedance spectroscopy (EIS) as a new tool for investigating methods of corrosion protection. Electrochim Acta 35:1533-1544

47. Keddam M, Mattos OR, Takenouti H (1981) Reaction model for iron dissolution studied by electrode impedance II. Determination of the reaction model. J Electrochem Soc 128:266-274 
48. Epelboin I, Gabrielli C, Keddam M, Takenouti H (1981) The study of the passivation process by the electrode impedance analysis. Compr Treatise Electrochem 4:151-192

49. Epelboin I, Keddam M (1972) Kinetics of formation of primary and secondary passivity in sulphuric aqueous media. Electrochim Acta 17:177-186

50. Sherif EM, Park SM (2006) Effects of 1,4-naphthoquinone on aluminum corrosion in $0.50 \mathrm{M}$ sodium chloride solutions. Electrochim Acta 51:1313-1321

51. Bockris JOM, Drazic D, Despic AR (1961) The electrode kinetics of the deposition and dissolution of iron. Electrochim Acta 4:325-361

52. Ashassi-Sorkhabi H, Nabavi-Amri SA (2000) Corrosion inhibition of carbon steel in petroleum/water mixtures by $\mathrm{N}$-containing compounds. Acta Chim Slov 47:507-517

53. Singh VP, Singh P, Singh AK (2011) Synthesis, structural and corrosion inhibition studies on cobalt(II), nickel(II), copper(II) and zinc(II) complexes with 2-acetylthiophene benzoylhydrazone. Inorg Chim Acta 379:56-63

54. Osman MM (1998) Hexadecyl trimethyl ammonium bromide as an effective inhibitor for the corrosion of steel in sulphuric acid solution. Anti Corros Methods Mater 45:176-180

55. Reinhard G, Rammelt U (1985) Proceedings of the 6th European symposium on corrosion inhibitors, Ferrara, Italy, p 831

56. Growcock FB, Jasinski RJ (1989) Time-resolved impedance spectroscopy of mild steel in concentrated hydrochloric acid. J Electrochem Soc 136:2310-2314
57. Kissi M, Bouklah M, Hammouti B, Benkaddour M (2006) Establishment of equivalent circuits from electrochemical impedance spectroscopy study of corrosion inhibition of steel by pyrazine in sulphuric acidic solution. Appl Surf Sci 252: 4190-4197

58. Econway B, Bai L (1986) State of adsorption and coverage by overpotential-deposited $\mathrm{H}$ in the $\mathrm{H}_{2}$ evolution reaction at $\mathrm{Au}$ and Pt. Electrochim Acta 31:1013-1024

59. Akbarzadeh E, Mohamad Ibrahim MN, Abdul Rahim A (2012) Monomers of lignin as corrosion inhibitors for mild steel: study of their behaviour by factorial experimental design. Corros Eng Sci Technol 47:302-311

60. Hosseini MG, Mertens SFL, Arshadi MR (2003) Synergism and antagonism in mild steel corrosion inhibition by sodium dodecylbenzenesulphonate and hexamethylenetetramine. Corros Sci 45:1473-1489

61. Ashassi-Sorkhabi H, Shaabani B, Seifzadeh D (2005) Corrosion inhibition of mild steel by some schiff base compounds in hydrochloric acid. Appl Surf Sci 239:154-164

62. Bentiss F, Lebrini M, Lagrenee M, Traisnel M, Elfarouk A, Vezin $\mathrm{H}$ (2007) The influence of some new 2,5-disubstituted 1,3,4thiadiazoles on the corrosion behaviour of mild steel in $1 \mathrm{M} \mathrm{HCl}$ solution: AC impedance study and theoretical approach. Electrochim Acta 52:6865-6872 